\title{
AVALAÇÃO FOTOBIOLÓGICA DE UMA MISTURA DE FILTROS SOLARES PHOTOBIOLOGIC VALUATION OF SUNSCREENS MIXTURE
}

\author{
Elisabete Pereira dos Santos'; Sheila Garcia; \\ Zaida Maria Faria de Freitas;3; Anneliese Lopes Barth ${ }^{4}$
}

${ }^{1}$ Profa . Adjunto - Departamento de Medicamentos da Faculdade de Famácia da UFR.
2Profa. Adjunto - Departamento de Medicamentos da Faculdade de Famácia da UFRJ.
${ }^{3}$ Famacêutica - Departamento de Medicamentos da Faculdade de Famácia da UFRJ.
${ }^{4}$ Mestranda em Ciênc ias Farmacêuticas- Faculdade de Farmácia da UFRJ.

\begin{abstract}
RESUMO
O principal objetivo deste trabalho foi avaliara eficácia de uma emulsão anti-solar contendo uma mistura de três filtros solares orgânicos: p-metoxicinamato de octila a 7,0\% + metil benzilideno cânfora a 3,0\% + p-metoxicinamato de isoamila a 3,0\%. O Fator de Proteção Solar (FPS) foi calculado in vitro por método espectrofotométrico. Foi feita a análise da fotoestabilidade da mistura por espectrometria e por cromatografia líquida de alta eficiência para determinar se os filtros sofrem fotodecomposição após serem iradiados com doses 10, 50 e 100 vezes superiores à dose nomal para formação de entema (DME). Foram rea lizados também testes de fototoxicidade e fotomutagenicidade para deteminar se a interação química oconida entre os filtros após as iradiações não conferiu nenhuma propriedade tóxica ou mutagênica à mistura.
\end{abstract}

Palavras-chave: Filtros solares, fotoestabilidade, fototoxicidade, fotomutagenicidade, eficácia.

\begin{abstract}
The objective of this work to evaluate the efficiency of the sunscreen lotion containing the three chemical sunscreens: octyl p-metoxycinnamate $7 \%$, methylbenzilidene camphor $3 \%$ and isoamyl p-metoxycinnamate $3 \%$. The Sun Protective Factor (SPF) was calculated using the in vitro spectrophotometric methods. The photostability of this combination was accessed using spectrophotometry in the $\mathrm{U}$ region and high performance liquid chromatography. The combination of sunsc reens was iradiated with doses 10, 50 and 100 higher than the minimal entemogenic dose (MED). Phototoxicity and photomutagenicity tests were also performed to evaluate if interactions that occured among the sunscreens after the inadiation gave any toxic or mutagenic character to the combination of sunscreens.
\end{abstract}

Key words: Sunscreens, efficiency, photostability, Phototoxic ity and photomutagenicity

\section{INTRODUÇÃO}

A redução da camada de ozônio aumentou em mais de $2 \%$ a incidência do câncer de pele, responsável por a proxima damente 8500 mortes/ano, só nos Estados Unidos ${ }^{1,2}$ De acordo com ERDMAN \& BERGOIL, ${ }^{3}$ existem duas ma neiras primánias de se reduzir o risc o de câncer de pele: evitara exposição ao sol entre 10:30 h e 15:00 h, horá rio em que a radiação é mais intensa, ou protegera pele quando a exposição é inevitável, usando filtros solares. Os filtros solares se tomaram uma ama essencial no combate aos efeitosagudos e crônicos provocados pela radiação solar. A crescente exposição à luz solar tomou o uso de filtros solares obrigatório. A diminuição da camada de ozônio juntamente com o aumento de ativida des a o arlivre reforçam a nec essidade do uso de filtros solarescom fatorde proteção solar (FPS) cada vez mais altos. Entretanto, o aumento da concentração de filtros numa formulação pode acarretar problemas como imitação cutânea e/ou instabilidade da preparação. 


\section{OBJ ETIVO}

O objetivo desse estudo foi avaliar uma mistura de filtros solares, buscando verific ara segurança de uso e eficácia, através de avaliações de Fator de Proteção Solar (FPS) in vitro $^{4,5}$, fotoestabilidade, fototoxicidade e fotomutagênicidade. A mistura avaliada, foi $p$ metoxicinamato de octila a 7\% + Metilbenzilideno cânfora a 3\% + p-metoxicinamato de isoamila a $3 \%$, apresentando em emulsão FPS in vitro $=22$.

\section{MATERIAL E MÉTODOS}

\subsection{TESTE DE FOTOESTABIUDADE}

Como já é descrito na literatura, o p-metoxic inamato de octila sofre fotodecomposição quando exposto a luz $\mathbb{V}^{6}$. Neste trabalho buscamos avaliar os efeitos da associação de filtros solares sobre esta fotodecomposição. O teste de fotoestabilidade foi realizado, submetendo a mistura de filtrosa dose de energia de: $2 \mathrm{KJ} / \mathrm{m}^{2}, 10 \mathrm{KJ} / \mathrm{m}^{2}$ e $20 \mathrm{KJ} \mathrm{m} \mathrm{m}^{2}$, ou seja doses 10, 50 e 100 vezes superior àquelas que uma pessoa poderia estarexposta num dia de verão ao meio dia. Os filtros foram analisados por espectrometria de UV para determinação dos FPS $^{4,5}$ e por cromatografia líquida de alta eficiência (CLAE) para deteminação de alterações que possam terocomido após as radiações (Tabela 1).

TABELA 1. FPS in vitro da mistura dos filtros em etanol antes e após a irradiação.

\begin{tabular}{|c|c|c|c|c|}
\hline \multirow{3}{*}{ Mistura dos Filtros em etanol } & \multicolumn{4}{|c|}{ FPS } \\
\hline & \multirow{2}{*}{$\begin{array}{c}\text { Antes da } \\
\text { inadiação }\end{array}$} & \multicolumn{3}{|c|}{ Apósa inradiação } \\
\hline & & $20 \mathrm{~K}$ & $10 \mathrm{~K}$ & $20 \mathrm{~K}$ \\
\hline $\begin{array}{l}\text { Octil metoxic inamato } 7 \%+ \\
\text { Metilbenzilideno cânfora } 3 \%+\text { Isoamil } \\
\text { p-metoxicinamato 3\%. }\end{array}$ & 22 & $17,2 \pm 0,23$ & $17,8 \pm 0,28$ & $17,2 \pm 0,23$ \\
\hline
\end{tabular}

Com doses de energia menores, há uma ligeira diminuição $(\cong 2)$ nos valores de FPS da mistura de filtros, porém há uma queda mais acentuada $(\cong 5)$ no FPSda mistura de filtros após a irra diação com doses de energia elevadas (20 KJ).

A análise da mistura por cromatografia líquidas de alta eficiência após exposição a luz $W$, demonstrou que ocorre algum tipo de interação química entre os filtros, que fazcom que o pico do p-metoxic inamato de isoamila aumentasse após a iradiação, porém ocorrendo uma diminuição nos valores de FPS.

\subsection{TESTE DE FOTOTOXICIDADE}

Os testes de fototoxic idade foram realizados com a mistura de filtros utilizando-se o teste com cobaias albinas Dunkin-Hartley, teste este já validado e utilizado em outros trabalhos ${ }^{7,8}$. Foram utilizados grupos de 4 animais que tiveram o dorso depilado, dividido em 4 áreas, onde se a plic ou em duas destas áreas $0,1 \mathrm{ml}$ da amostra, e nas outras duas, 0,1 $\mathrm{ml}$ de uma solução padrão de 8 metoxipsoraleno como padrão de fototoxicidade. Os 
a nima is foram expostosa lâmpadas de luznegra de 15 Watts de potência e de comprimento de onda de 300-390 nm (UVA) porduas horas (Figura 1).
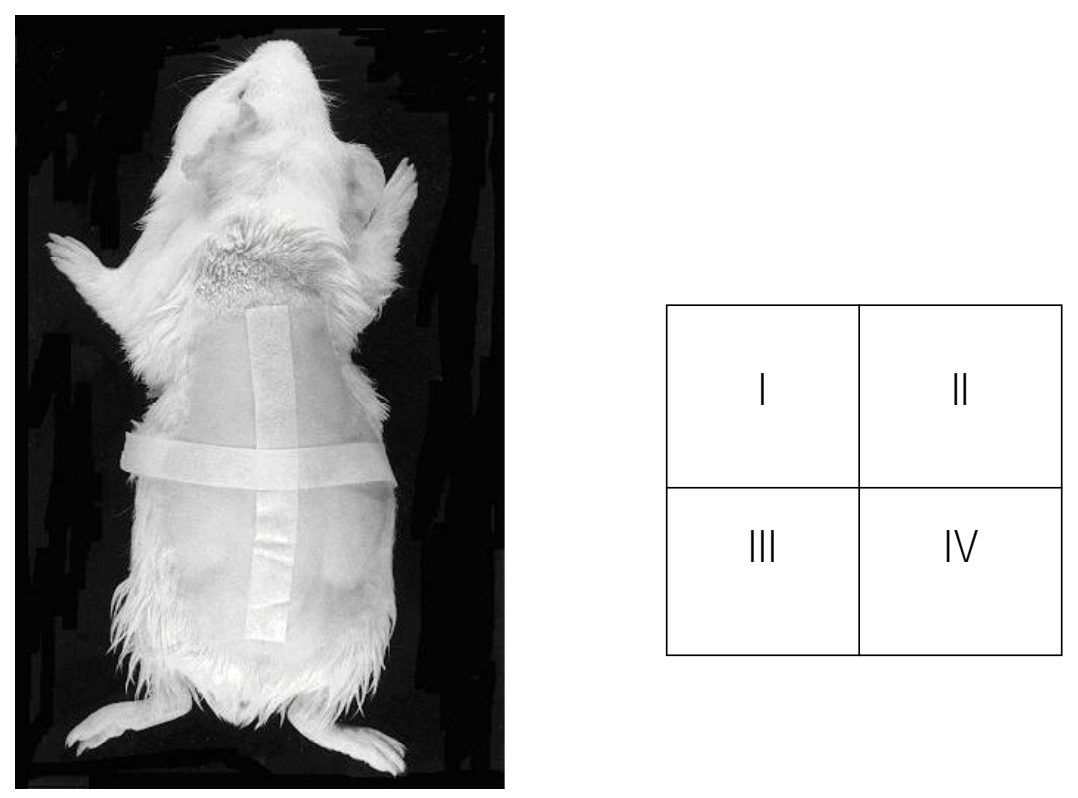

Onde:

l: amostra iradiada

Il: padrão imadiado

III: amostra não iradiada

IV: padrão não iradiado

FIGURA 1: Descrição da divisão do dorso do animal para a plicação das amostras e posterior ima diação.

Após 24 e 48 horas à exposição os anima is foram observados e o grau de eritema formado foi classificado segundo a escala.

\begin{tabular}{|l|l|}
\hline $0=$ nenhuma reação & $1=$ entema fraco \\
\hline $2=$ entema moderado & $3=$ entema forte \\
\hline
\end{tabular}

Os valores dos índic es de fototoxic idade da mistura dos filtros podem ser observados na tabela 2.

TABELA 2. Valores dos índices de fototoxicidade da mistura dos três filtros sola res e do 8 metoxipsoraleno na epideme de cobaias após a exposição à radiação UVA, por 2 horas.

\begin{tabular}{l|c|c}
\multicolumn{1}{c|}{ Indução } & Incidência & Índice de Fototoxic idade \\
\hline 8-metoxipsoraleno + UNA & $4 / 4$ & $1,625 \pm 0,377$ \\
\hline 8-metoxipsoraleno & $0 / 4$ & 0 \\
\hline Mistura dos 3 filtros + UNA & $0 / 4$ & 0 \\
\hline Mistura dos3 filtros & $0 / 4$ & 0 \\
\hline
\end{tabular}

Como pode serobservado, a mistura de filtros não provocou nenhum tipo de reação fototóxic a na epideme das cobaias após a exposição por duas horas à radiação UVA.

\subsection{TESTE DE MUTAGENICIDADE}

Para avaliamos se os filtros solares que compõem a mistura e se a mistura em si são mutagênic os, rea lizou-se o SOSC romoteste. ${ }^{9} \mathrm{O}$ teste foi feito utilizando-se 2 cepas de $\mathrm{E}$. 
coli, PQ35 (uvr-), selvagem e PQ37 (uvrA), mais sensível. As cepas foram incubadas inic ialmente com $100 \mu \mathrm{l}$ dos compostos testados. Em seguida realizou-se o teste com a CEPA PQ37 com 300ul dos compostos testados para melhor visualização dos resultados. Após um peńodo suficiente para síntese de proteína, a atividade da ß-galactosidase foi testada. Foi feito um controle positivo usando-se 4NQO, substância sabidamente mutagênica, e um controle negativo utilizando-se etanol absoluto. Foram testados separadamente os filtros p-metoxic inamato de octila, metil benzilideno cânfora e p-metoxic inamato de isoamila em etanol, a mistura dos 3 filtros em etanol e a mistura dos 3 filtros em emulsão (Tabela 3 ).

TABELA 3. Resulta do da indução de mutagenicidade a pós irradiação com luz ultravioleta A dos filtros solares e da mistura destes filtros em cepas de $E$. coli.

\begin{tabular}{l|c|c|c}
\hline $\begin{array}{l}\text { Resultado da indução de mutagenicidade após imadiação } \\
\text { com luz ultra violeta A dos filtros solares e da mistura destes } \\
\text { filtros em cepas de E. coli. } \\
\text { C OMPOSTO }\end{array}$ & $\mathbf{1 0 0 \mu l}$ & $\mathbf{1 0 0 \mu l}$ & $\mathbf{3 0 0 \mu l}$ \\
\hline \begin{tabular}{l|c|c} 
Controle positivo - 4NQO \\
Controle negativo - Etanol
\end{tabular} & $(+)$ & $(+)$ & $(+)$ \\
\hline p-metoxicinamato de octila/Etanol & $(-)$ & $(-)$ & $(-)$ \\
\hline Metilbenzilideno cânfora/Etanol & $(-)$ & $(-)$ & $(-)$ \\
\hline p-metoxicinamato de isoamila/Etanol & $(-)$ & $(-)$ & $(-)$ \\
\hline Mistura dos 3 filtros/Etanol & $(-)$ & $(-)$ & $(-)$ \\
\hline
\end{tabular}

\section{CONCLUSÃO}

A mistura avaliada, foi p-metoxic inamato de octila a 7\% + Metilbenzilideno cânfora a $3 \%+p$-metoxic inamato de isoamila a $3 \%$, tendo in vitro em emulsão FPS $=22$.Os testes de fototoxic ida de foram realizados com a mistura de filtros utilizando-se o teste com cobaias albinas Dunkin-Hartley. A mistura de filtros não provocou nenhum tipo de reação fototóxica na epideme dos cobaias a pós a exposição porduas horas à radiação UVA. Realizou-se o SOSCromoteste para verificara mutagênic idade dos filtros. Os resultados do SOScromoteste demonstraram que os filtros solares analisa dosnão são mutagênicos nem quando testa dos isoladamente nem quanto presentes na mistura proposta. A análise da mistura por cromatografia líquidas de alta eficiência após exposição a luz $W$, demonstrou que ocorre algum tipo de interação química entre os filtros, que faz com que o pico do $p$ metoxicinamato de isoamila aumentasse após a imadiação, apesar da análise por espectrofotometria ter demonstrado que a proteção proporcionada pela mistura diminui (expressa em temos do seu FPS). A mistura de filtros proposta não possui nenhuma propriedade tóxica ou mutagênica que pudesse ser detectada pelos testes empregados neste trabalho.

\section{REFERÊNCIAS}

1. FILGUEIRA, A. L Envelhecimento cutâneo: Prevenção. An. Bras. Derma tol., Rio de J aneiro, v. 66, n. 5, p. 14S-16S, 
1991.

2. TAYLR, J. S. DNA, sunlight and skin cancer. Pure \& Appl. Chem., v. 67, n. 1, p. 183- 190, 1995.

3. ERDMAN, K. L, BERGOIL, S. C. Safe tan an oxymoron. Cancer Nursing, v. 16, n. 2, p. 139-144, 1993.

4. SANTOS, E. P. , FREIAS, Z M. F., SOUZA, K. R, GARCIA, S. in vitro and in vivo determination of sun protection factor of sunscreen lotions with octylmethoxycinnamate. Int. J. Cosmet. Sci., v. 21, p. 1-5, 1999.

5. MANSUR, J . S. et al. Determinação do Fatorde Proteção Solarpor Espectrofotometria. An. Bras. Dema tol., v. 61 n. 3, p. 121-124, 1986.

6. SCHWARTLENBACH, R, BERTSCH, L Determination of photostability in diluted solutions. In: Betwenn-Congress Conference, Montreaux, 1995, p. 277-282 (Preprints IFSCC).

7. BUEHLER, E. V., NEWMANN, E. A., PARKER, R. D. Use of the occlusive patch to evaluate the phtosensitive properties of chemicals in guinea-pigs. Fd. Chem. Toxic. v. 23, p. 689-694,1989.

8. RAMOS, M. F. Perspectivas da utilização dos Extratos de Própolis, Aloe spp. e Hamamelis virginia na. Rio de J aneiro, Faculdade de Famácia da UFR, 1995 (Tese de Mestrado em Ciências Famacêuticas).

9. GUIШARDET, P. HOFNUNG, M. The SOS chromotest, a colorimetrical bac terial assay for genotoxins: procedures. Mutation Research, v. 147, p. 65-78, 1985. 